\title{
Research on the infiltration of environmental protection consciousness in the teaching of chemistry teachers' specialty
}

\author{
Sheng-Jie Jiang, Zheng-Hao Fei *, Jing-Ping Wang \\ School of chemistry and environmental engineering, Yancheng Teachers University, Jiangsu, 224007, China
}

\begin{abstract}
As a chemistry teacher, this paper studies the recycling of experimental drugs and the treatment of three wastes in the middle school chemical demonstration experiment from the perspective of environmental protection. The concept of experimental environment-friendly was emphasized, and the concept of environmentally friendly chemistry and green chemistry education was established, and this concept into the future chemistry teaching of middle school was put. In this way, it achieves the training goal of chemists and environmental education functions, and also achieves the penetration of environmental protection awareness in middle school chemistry teaching.
\end{abstract}

Keywords Environmental protection awareness; chemistry teacher major; environmentally sound chemical education; three waste treatment

DOI: $10.7176 / \mathrm{JEP} / 10-6-12$

\section{Introduction}

Since the 20th century, the rapid development of science and technology has created enormous material wealth for human beings, but at the same time, with the development of production, the transitional development and consumption of natural resources, the discharge of a large number of pollutants, the environment for human survival has changed. It caused a series of environmental problems. Such as more floods, deterioration of water quality and ecology, sand and dust invasion, the use of refrigerant Freon caused ozone hole, greenhouse effect, acid rain and so on. Therefore, it is urgent to strengthen the awareness of environmental protection in the teaching of chemistry teachers' specialty. It is the duty of every chemical teachers' student to infiltrate environmental education into chemistry teaching in middle schools, cultivate good habits of environmental protection and raise the awareness of environmental protection of the whole people. It is also a long-term and effective measure of environmental protection.

\section{Expanding classroom content and strengthening environmental harmless chemistry education}

In junior middle school chemistry teaching, students are exposed to water, air and soil. In these three parts of the study, we can strengthen the teaching of environmentally sound chemistry [1-4]. The chapter "Air around us" focuses on the study of oxygen and carbon dioxide. Teachers should attach great importance to the content of teaching materials and strengthen the education of environmentally sound chemistry. For example, when we study carbon dioxide, we can introduce it to students. Although we often hear that carbon dioxide is the "culprit" of the greenhouse effect, it seems that carbon dioxide is a great evil and can not survive in the world. Teachers should give students a dialectical view of carbon dioxide. The greenhouse effect is caused by carbon dioxide, but the greenhouse effect is not a derogatory term. When the sky is dark at night, if carbon dioxide does not hold heat and regulate the temperature difference, the temperature difference between day and night on the earth will be very large. Human beings can not even survive and plants can not grow. In addition to trapping heat, green plants need carbon dioxide for photosynthesis to provide nutrients for their own growth. The ideal concentration of carbon dioxide is $0.03 \%$ of air volume fraction. In recent years, due to the lack of awareness of environmental protection, excessive cutting of trees and destruction of forests, the number of green plants on the surface has decreased dramatically, resulting in carbon dioxide can not be absorbed by green plants in time, the rapid development of industrial economy, the use of a large number of cheap and environmentally friendly fossil fuels, which makes the concentration of carbon dioxide continue to rise, breaks the original balance and leads to greenhouse efficiency. It should be intensified that the heat can not be released from the ball in time, the global climate is rising and the number of extreme weather is increasing, thus causing a series of problems such as soil desertification and sea level. To solve these problems, we need to make use of the knowledge of environmental courses to promote the use of green and environmentally friendly new energy sources, such as solar energy, wind energy, geothermal energy and so on.

For example, in the process of teaching, we should not confine our thinking to books, but supplement some extra-curricular knowledge appropriately. For example, with the help of lightning, nitrogen can be used as nitrogen fertilizer for plant roots. In the food packaging industry, it is also a very good food protective gas. Only when students feel the real use of chemicals in our lives, they will use an objective perspective to see these chemicals. Without man-made destruction, all gases in the atmosphere are in a delicate and harmonious dynamic equilibrium. However, the excessive emission of carbon dioxide, nitrogen oxides and sulfur oxides into the air caused by the massive use of fossil fuels has broken the original balance, polluted the fresh air, and brought great 
disasters to human beings by polluted air. Acid rain has produced, destroyed forests, polluted soil and crops, acidified lakes, and sharply reduced the number and species of animals and plants in the water. The corrosiveness of acid rain destroys ancient buildings and reduces the service life of industrial equipment. The excessive use of CFCs to make refrigerants and so on has seriously damaged the ozone layer, and the ozone layer's ability to absorb ultraviolet radiation has also been weakened. Once ultraviolet radiation is enhanced, people can umbrella and hide under buildings, but plants have nowhere to hide, their production has been reduced, and their physiological structure has been seriously damaged. The extra-curricular knowledge enables students to realize that air is closely related to our lives. Our human actions can change our ecological environment. Human beings can not discharge exhaust gas at will to destroy the atmospheric balance.

In the study of Water Composition, environmental knowledge can also be used to help students build up environmental awareness. For example, when exploring the composition of water by electrolysis, after introducing the chemical properties of hydrogen to students, supplementing hydrogen is a very good green energy. Homeopathic causes students to think about other clean energy sources. Let the students know that water is composed of hydrogen and oxygen, at the same time, we should also combine textbooks to add to the students: China's freshwater resources are relatively poor, we are one of the thirteen poor countries in the world, and water pollution is very serious, it is water quality shortage. The fundamental reason for water pollution is that raw materials, reactions and products are not green, and the wastewater after reaction is not treated reasonably. The relationship between water pollution and environmentally harmless chemistry is clarified. Therefore, we strengthen students' environmental awareness and help students establish the environmental protection concept that wastewater should be treated and discharged again.

In the study of "Elements", we teach students common elements, trace elements, but also related to the content ranking of crustal elements. In the textbook, we simply introduced the ranking of elements in the crust, but we did not mention what harm would happen if some elements exceeded the standard, and how we should protect land security, which needs to be supplemented by teachers. Teachers should emphasize the importance of protecting land to students. Land is the source of all production and all existence. Human beings' food, clothing, shelter and transportation are all derived from land. Because of the growth of population and the rapid development of industry, we constantly manufacture industrial wastes and domestic refuse. Solid wastes, hazardous solids and garbage are buried in the land, wastewater seeps into the land, harmful gases and garbage. Harmful particulate matter also enters the soil by rainwater, and the soil is seriously polluted. In addition to reducing the yield and quality of crops, mercury, cadmium and other heavy metals are enriched in the fruits of crops. They are eaten by human beings and enter the human body. They cause harm to human body and seriously affect human health. Therefore, the protection of soil safety means the protection of human beings themselves, which requires us to deal with industrial and chemical laboratory wastes reasonably. Because of the limitation of class hours, the pressure of examination results, in middle school learning, schools and teachers have no time and energy to set up a separate environmental education course. The environmental protection concept that students usually come into contact with comes mostly from teachers' imparting and immersion in life. Therefore, as a future chemistry teacher, we will incorporate these environmental protection concepts intangibly into the environmental harmless chemistry education in the ordinary classroom with ingenious methods.

\section{Integrating the concept of "environmentally sound chemistry" into chemical experiments}

There will be a lot of experiments in middle school learning. One part is teachers' demonstration experiment, the other part is exploratory experiment, and the other part is assessment experiment. No matter what kind of experiment, students are full of strong interest and study with $100 \%$ enthusiasm. Therefore, chemical experiment is the best medium for environmental harmless chemistry education. Integrating the relevant content of "environmental harmless chemistry" into experimental teaching is conducive to cultivating students' awareness of environmental protection, and plays a positive role in students' follow-up chemical learning. To implement and promote environmentally sound chemistry, chemistry teachers can start from the following aspects [5-6].

\subsection{Organic combination of teaching contents}

In the process of chemistry teaching, the content of experiment course should be representative and unique. Teachers should try to compress the repetitive parts of high school chemistry, so as to reduce the waste of class hours and experimental resources and the production of three wastes of experiment. In this way, we can reduce the waste of class hours and experimental resources, and reduce the production of three wastes of experiment. For example, in the process of junior middle school teaching, students first learn the nature of carbon dioxide, and then carry out the experimental course of carbon dioxide production, because students have learned the chemical nature of oxygen and the production of oxygen before. It lays the foundation of knowledge and experiment for the study of carbon dioxide. When we study the nature and production of carbon dioxide, we can combine the two. Learning in experiment can not only stimulate students' interest in learning, but also save experimental resources. Teachers do not need to prepare carbon dioxide for classroom effects alone (see Table 1). 
Table1 Experiments on the preparation and properties of carbon dioxide

\begin{tabular}{|c|c|c|c|c|}
\hline Experiments & objective & solid waste & Liquid waste & waste gas \\
\hline Experimental & Master the & \multirow{5}{*}{$\begin{array}{c}\text { Limestone } \\
\text { granules }\end{array}$} & & \\
\hline Activity II & Laboratory & & Dilute & A small amoun \\
\hline Laboratory & Production and & & hydrochloric acid & of hydrogen \\
\hline preparation and & Chemical & & and calcium & chloride gas \\
\hline $\begin{array}{l}\text { properties of } \\
\text { carbon dioxide }\end{array}$ & $\begin{array}{c}\text { Properties of } \\
\text { Carbon Dioxide }\end{array}$ & & $\begin{array}{l}\text { chloride mixed } \\
\text { solution }\end{array}$ & \\
\hline Experiment 6-3 & Carbon dioxide is & \multirow[t]{3}{*}{ candle } & & \\
\hline $\begin{array}{l}\text { Carbon dioxide } \\
\text { extinguishing }\end{array}$ & denser than air. & & & \\
\hline candle experiment & & & & \\
\hline Experiment 6-4 & \multirow{2}{*}{$\begin{array}{l}\text { Carbon dioxide is } \\
\text { soluble in water }\end{array}$} & & & \\
\hline $\begin{array}{l}\text { Water solubility } \\
\text { experiment of } \\
\text { carbon dioxide }\end{array}$ & & & $\begin{array}{l}\text { Water solution of } \\
\text { carbon dioxide }\end{array}$ & \\
\hline Experiment 6-5 & Understanding the & & Carbonic acid & \\
\hline Chemical & Chemical & & solution & \\
\hline Properties of & Properties of & & & \\
\hline Carbonic Acid & Carbonate & & & \\
\hline
\end{tabular}

For example, in learning the conditions of combustion and the principle of fire extinguishing (see Table 2), there are actually no two experiments. Students can draw three points from the experiments of combustion conditions: 1. Material must be combustible; 2. The ignition point under material standard condition; 3. Full contact between combustible and oxygen. To explore the method of fire extinguishing, as long as we follow the train of thought back to infer: 1, isolate air or oxygen, 2 , reduce the temperature below the ignition point. In this way, unnecessary experiments can be deleted, experimental costs can be saved, and the teaching goal of environmentally sound chemistry can be achieved.

Table 2 Combustion and Fire Extinguishing Experiments

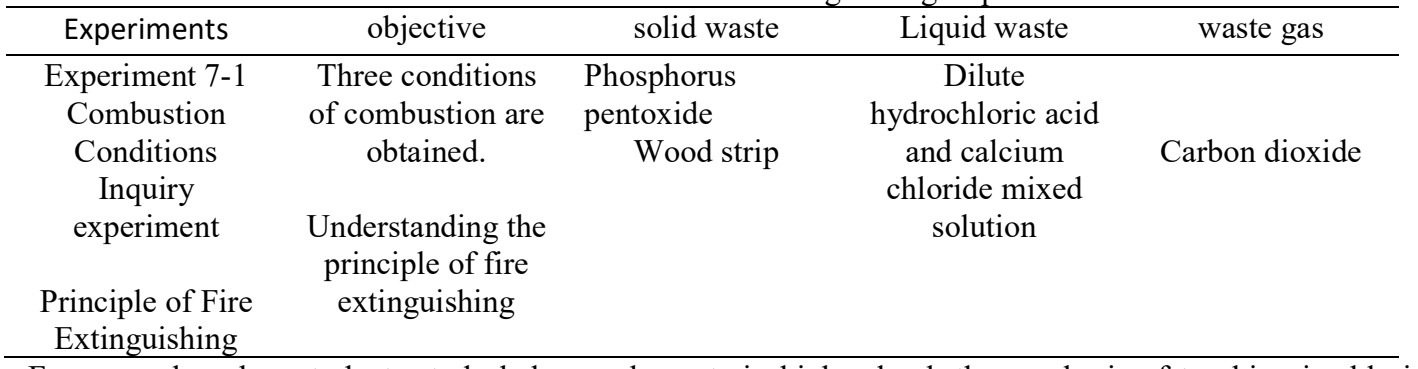

For example, when students study halogen elements in high school, the emphasis of teaching is chlorine element. When they study the chemical properties of chlorine gas and chlorine water, the chlorine water can be used not only to explore the chemical properties of chlorine water, but also to oxidize iodine and bromine ions into iodine and bromine (see Table 3). When we do these two experiments together, we can not only save drugs and reduce the emission of three wastes, in line with the concept of green chemistry, but also lay a foundation for students to learn bromine and iodine elements.

Table 3 Experimental properties of chlorine gas

\begin{tabular}{|c|c|c|c|c|}
\hline Experiments & objective & solid waste & Liquid waste & waste gas \\
\hline $\begin{array}{c}\text { The experiment } 9 \\
\text { Chemical } \\
\text { properties of } \\
\text { chlorine water }\end{array}$ & $\begin{array}{c}\text { To master the } \\
\text { chemical } \\
\text { properties of } \\
\text { hypochlorous acid } \\
\text { and chlorine gas }\end{array}$ & $\begin{array}{c}\text { Faded strips } \\
\text { Iodine elemental }\end{array}$ & Chlorine water & $\begin{array}{l}\text { Chlorine } \\
\text { chlorine }\end{array}$ \\
\hline $\begin{array}{l}\text { The experiment } \\
10 \\
\text { Extraction of } \\
\text { bromine and } \\
\text { iodine }\end{array}$ & $\begin{array}{l}\text { Grasp the } \\
\text { oxidability of } \\
\text { chlorine } \\
\text { molecules }\end{array}$ & & & \\
\hline
\end{tabular}




\subsection{Recycling of experimental drugs}

Environmental stresses in classes to maximize the resources in the middle school chemistry experiments can have very good guide effect, so as to inspire us to think about how the experiment class of chemical experiment material reuse, therefore, we should make scientific chemical experiment process management, to produce the goods such as waste gas, waste residue centralized collection, and then unified to professionals for chemical processing and recycling test items, the product of some experiments can be collected, as a new experiment of reactant, this can reduce the waste of material in chemical experiment, and achieve the goal of recycling, In this way, pollution caused by chemical experiments can be reduced [7].

The reactants in the part of the chemical reaction can be directly recycled, generally the reactants has the following characteristics: solid, relatively stable chemical properties, such as metal in inquiry activity sequence is used when the copper, iron nails, aluminium, and used in hydrogen peroxide producing oxygen trial manganese dioxide as catalyst, and the carbon dioxide of preparing and chemistry inquiry experiment used limestone, candles, etc. The candles themselves do not need to be processed to continue using.

For example, the product of ammonia water solubility exploration experiment is ammonia water solution. If the ammonia solution is discharged directly through dilution, it will waste water resources and not be environmentally friendly. The ammonia solution can be collected and used to configure the silver ammonia solution for the silver mirror reaction. Again as in the reaction of sodium and water experiment, sodium metal react with water to generate sodium hydroxide solution, sodium hydroxide solution has strong corrosive, processing up more troublesome. Sodium hydroxide solution can be concentrated, through heating to obtain sodium hydroxide solid, sealed dry preservation, but also the dilute solution of sodium hydroxide, heating to make it into a concentrated solution. As an acid gas absorbent in some reaction tail gas treatment. Such as copper in the reaction with nitric acid and concentrated sulfuric acid, copper will produce SO2 and NO2 gas. Sulfur dioxide and nitrogen dioxide are harmful gases. If they are directly discharged into the air, they will cause the harm of acid rain. We can use the previously collected sodium hydroxide solution to absorb them. The resultant sodium sulfate and sodium nitrate can be used as reactants in the test of ions in the salt solution [8].

In addition, we need to set up the "green cycle" experimental system, which is the most typical of the experiments of carbon cycle. In the chemical experiment of middle school, the carbon dioxide is the most contacted laboratory air waste, although the quantity generated in the test is not much, but the accumulation is very harmful. In the modern society, where the greenhouse effect is becoming more and more serious, the energy saving and emission reduction, the low-carbon environment is not only needed to go from the lower carbon, the lower carbon, the lower carbon, the lower carbon is the lower carbon, but the experiment on the carbon dioxide in the laboratory starts with the reaction of dilute hydrochloric acid and calcium carbonate to make carbon dioxide, The carbon dioxide can be tested with clarified calcium hydroxide solution, which can generate calcium carbonate in the reaction of carbon dioxide and calcium hydroxide. We can collect the carbon dioxide generated in the experiment, absorb it with alkaline lime or concentrated sodium hydroxide solution, and generate carbonate, which can be used as the reactant in other experiments, so as to achieve the purpose of low carbon and environmental protection [7].

\subsection{Improve experimental drugs and reaction devices}

In our chemical experiments in middle school, harmful substances and environmental pollution are generated in some experiments, and we can improve in several ways.

\subsubsection{Choose environment-friendly and green medicine}

In the test of the preparation of oxygen, the traditional experiment was selected by using potassium permanganate, but the potassium permanganate reaction was completed and the potassium manganate and manganese dioxide were generated, and the reaction was incomplete, resulting in complex solid waste products, and it was necessary to ensure that the test tube was completely dry, and if the experiment was wet, the weather was humid, the potassium permanganate was in itself with moisture, in the experiment, there would be a lot of water in the test, which could cause the test tube wall to adhere to a layer of gray brown paste, which is very difficult to wash. Hydrogen peroxide can be dissolved to produce oxygen. Hydrogen peroxide can be decomposed to generate water and oxygen. If the reaction is sufficient, no hydrogen peroxide remains.

\subsubsection{Improved reaction unit}

Many of the experiments in high school experiments produce harmful substances into the air, and in the iron smelting experiment, the book introduces a non-reactive carbon monoxide that usually fires directly into carbon dioxide (see picture 1). It is then discharge into that air, which is a waste of the greenhouse effect, and the carbon monoxide itself is a fuel, and we can add a glass bend over the traditional device map, which can ignite the unreacted carbon monoxide to the wine accuracy (see FIG. 2), which can be used as the fuel for the reaction, which solves both the emission problem of the carbon monoxide and the fuel economy, which can meet the requirement of the environment-friendly chemical [9]. 


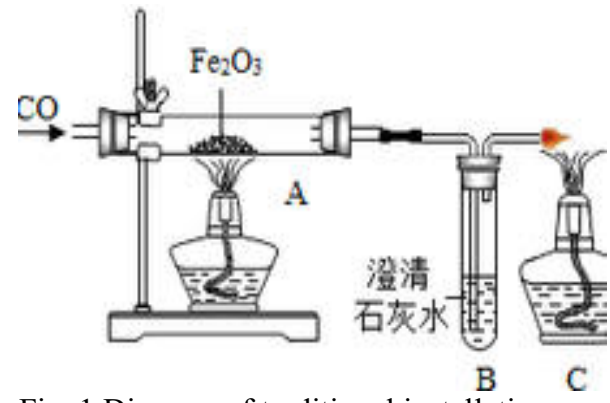

Fig. 1 Diagram of traditional installation

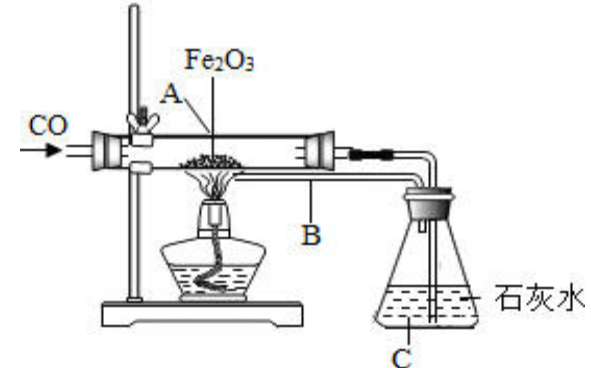

Fig. 2 Improvement device diagram

\subsection{Substitute teaching video for toxic and dangerous experiment}

In chemistry teaching of middle school, some experiments are required to be more rigorous, such as the reaction between hydrogen gas and chlorine gas, which are learnt in textbooks, which can cause the gas collection cylinder to explode, glass splash, and injury if the amount of reaction and light intensity cannot be controlled. This experiment was previously required as a classroom demonstration experiment in high school, but now it is mostly replaced by video experiment. Such as the development of a new mobile phone software "beaker" software design more than 150 agents, can try to more than 300 kinds of chemical reaction, can let the students on a mobile phone to do all kinds of chemical experiment, such as active metal like this kind of risk a great deal of experiments, the student can safely use virtual software to complete, so, won't cause pollution to the environment, at the same time observe the experiment phenomenon, familiar with the operation process, also can stimulate interest in chemistry learning, the best of both worlds.

\subsection{The experiment is miniaturized}

Micro experiments are to reduce the dosage of drugs, and use the micro-design laboratory instruments for experiment. The good thing is that the dosage is low, the pollution is small, and the experiment is clear. In addition to the requirements of the curriculum standard, which clearly stipulates the student union's operation and the eight experimental operation steps of the examination and assessment, most of the other experiments are demonstrated by teachers, whose purpose is to show the experimental phenomena and arouse students' thinking. The use of micro experiments, not only will not affect the phenomenon of the experiment, but also can save costs, cultivate the spirit of innovation and development of students. With sodium water reaction experiments, for example, a shortcoming of the traditional experiments in, if you take too much sodium metal, reaction would be too intense, even an explosion, on the other hand, the generated hydrogen is not easy to collect, the poor safety [10].

After the experiment was improved (see figure 3), we first filled a certain amount of water in the u-shaped pipe, one end was plugged with a single-hole plug, the other end was added with a certain amount of kerosene, and then a few grains of sodium were added, and then the pipe mouth was quickly plugged with a single-hole plug. At this point, when the gas from the upper airway with a pointed nozzle is produced, the water is squeezed into the funnel. The rise of water surface can form pressure on hydrogen, which is favorable for gas ignition. After improving the experiment, the gas produced is easy to collect and saves medicine.

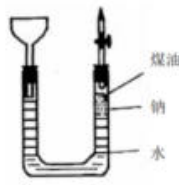

Fig. 3 Miniaturization improvement of sodium and water reaction experiment

\subsection{Middle school experiment greening of "three wastes" treatment}

After the experiment, some by-products will be produced. Teachers cannot ignore the effects of these substances, so they need to deal with them reasonably. For example, the waste acid and alkali produced in the experiment can be used as the absorption solution of exhaust gas, and the unreacted drugs can also be recycled through washing and drying. The hazard reduction shall be achieved if the utilization cannot be recycled, and the environmentally harmless re-emission shall be possible as far as possible. The proper disposal and recycling of the experimental wastes in middle school not only protect the environment, but also enrich the classroom contents. Learn from that teaching and the combination of the teaching and teaching, and the environmental protection consciousness of middle school students is cultivated in the invisible.

\section{Conclusion}

Environmental protection has a long way to go. It needs not only the governance of our generation, but also the careful protection of future generations. Environmental education is the most basic, comprehensive and 
effective measure to solve environmental problems. With great significance and far-reaching influence, school is an important place for teenagers to cultivate their awareness of environmental protection and ability to participate. As the teacher in the future, the quality of the normal school students will determine that the education, education is accepted by the students in the school, which will also affect their environment view, indirectly determine their attitude and approach to environmental protection. In view of this, the environmental protection awareness in the chemical normal professional education is connected with the chemical experiments of the middle school, emphasizing the "three wastes" green treatment, cultivating the environment thinking of the system, and transporting more talents with environmental thinking to various sectors of the society.

\section{Acknowledgement}

The research is supported by a Project Funded by the brand professional project form Yancheng teachers university (2016), the teaching reform and practice of medicinal chemistry (17YCTCJY011) 、 (12YCTCJY011)and A Project Funded by the Excellent Specialties Program Development of Jiangsu Higher Education Institutions (PPZY2015B113).

\section{References}

[1] Gui-Lin Fang. (2017). Case study of infiltration environment education in chemistry teaching. Reference for chemistry teaching in middle school.46(8): 23-24.

[2] Yu-Xin Lu. (2008). Research on the infiltration of green chemistry concept in high school chemistry teaching. Journal of the road to success. 19 (1) : 56-57.

[3] Yu-Lan Hao, Rong-Ming Zhang, Jun Wang, Xiao-Fei Zhao, Ting-Ting Jiang, Qin Yu. (2012).Exploration and practice of green chemistry experimental teaching system. Journal of Laboratory Science. 15 (5): 9-10, 13.

[4]Hong Chen. (2003). Investigation and reflection on the cultivation of students' environmental consciousness in chemistry teaching in ordinary middle schools. Journal of Chemistry Dducation. 24 (10) : 38-40.

[5] Ii-Mei Wang, Zhao-Fu, Zen-Qiang Zhang, et al. (2012). Research on green chemistry education in high school chemistry teaching. Journal of educational research. 11(1): 127-147.

[6] Yan-Duo Zhou. (2010).Infiltration of environmental protection consciousness in chemistry teaching. Journal of modern educational equipment. 8 (12) : 105-106.

[7] Yang-Hua Cao.(2014).Strengthening environmentally sound chemistry education in junior high school chemistry teaching. Journal of educational research.12(1): 67-69.

[8] Yi-Ping Lu. (2018). Teaching reform of high school chemistry experiment based on the concept of "green chemistry". Journal of new curriculum.14(1): 59-61.

[9] Rong Lu, Xue-Zeng. (2013).Determination of oxygen content in air by pyrogallol method. Journal of chemical education. 3(1): 56-58.

[10] Lin-Tao Zeng. (2017). Exploration of green chemistry experiment in middle school. Journal of teaching research of course materials. 7(8): 26-28. 